\title{
Past, present and Future Oncology: welcome to volume 17
}

\author{
Louis Gautier*, 1 iD \\ ${ }^{1}$ Future Medicine Ltd, Unitec House, London, N3 1QB, UK \\ *Author for correspondence: I.gautier@futuremedicine.com
}

"We are very pleased to welcome readers to the 17th volume of Future Oncology."

First draft submitted: 7 December 2020; Accepted for publication: 7 December 2020; Published online: 6 January 2021

Keywords: content highlights $\bullet$ COVID-19 $\bullet$ highly read content $\bullet$ oncology $\bullet$ real-world evidence $\bullet$ social media

We are very pleased to welcome readers to the 17th volume of Future Oncology. As in previous years, we like to start this issue by taking a look at some content highlights from 2020 and to update you on all the work that the editors have done over the course of the year.

We are also pleased to welcome Roshaine Wijayatunga - Senior Editor of Oncology and Commissioning Editor for Future Oncology - back from maternity leave. She has been a long-valued member of the editorial team and we are all very much looking forward to our eventual return to the office.

It certainly cannot be argued that the global coronavirus pandemic drew the most focus from the scientific community throughout 2020 . Oncologists were quick to muster to the new environment so we will take you through some of the foremost articles on COVID-19 and cancer from our authors, as well as explain how we continued the publication of timely, high quality and impactful manuscripts throughout the year.

\section{Content highlights from 2020}

In recent years, an increasing emphasis has been placed on the inclusion of patients in medical research, both at a governmental level and within individual institutions. An important part of this is ensuring that the output from medical research is available in a format accessible to all. Future Science Group is keen to recognize and support patients, both as contributors and readers [1]. To this end, Future Oncology recently published our first Plain Language Summary of Publication [2], which provides a visually enriched summary of the recently published ENLIVEN study, investigating pexidartinib for tenosynovial giant cell tumor [3].

Unsurprisingly, articles discussing COVID-19 and the unique considerations for cancer patients have featured heavily throughout 2020. Initially, we received a wealth of real-world data collection aiming to understand the disease's impact on cancer and vice versa, followed by a series of shorter articles considering how the infection could be avoided and how treatment should be adjusted. One notable early submission was a research article describing the reorganization of a medical oncology department in the Italian Emilia Romagna region (a hotspot in the initial wave of the pandemic), submitted by one of Future Oncology's Editorial Board Members Alba Brandes and her team $[4]$.

One of the most-read articles on COVID-19 was an editorial by Elkaddoum et al. (Saint Joseph University of Beirut, Beirut, Lebanon), which discussed the opportunity of using the pandemic to establish telemedicine as a crucial component of healthcare [5]. This editorial was particularly rewarding to work on as, shortly following publication, we received a Letter to the Editor from two medical students at Barts Cancer Institute (London, UK) describing how this opportunity could also allow medical students to gain valuable experience and replace some educational opportunities that were missed as a result of the pandemic. This correspondence appears in this issue of the journal [6].

Table 1 shows the most highly-read content from Future Oncology at the time of writing (December 2020). The most-read article, the final GioTag analysis from Hochmair et al. is the culmination of a global observational study

Future 8 Medicine 
Table 1. Top three Future Oncology articles.

\begin{tabular}{|c|c|c|c|c|}
\hline Rank & Title & Authors & $\begin{array}{l}\text { Page } \\
\text { views/downloads }\end{array}$ & Ref. \\
\hline 1. & $\begin{array}{l}\text { Sequential afatinib and osimertinib in patients with } \\
\text { EGFR mutation-positive non-small-cell lung cancer: final } \\
\text { analysis of the GioTag study }\end{array}$ & $\begin{array}{l}\text { Hochair MJ, Morabito A, Hao D, Yang CT, Soo RA, Yang } \\
\text { JCH, Gucalp R, Halmos B, Märten A \& Cufer T }\end{array}$ & 15,594 & [7] \\
\hline 2. & $\begin{array}{l}\text { Suspected cancer symptoms and blood test results in } \\
\text { primary care before a diagnosis of lung cancer: a } \\
\text { case-control study }\end{array}$ & $\begin{array}{l}\text { McDonald L, Carroll R, Harish A, Tanna N, Mehmud F, } \\
\text { Alikhan R \& Ramagopalan SV }\end{array}$ & 8390 & [8] \\
\hline 3. & $\begin{array}{l}\text { Therapies after first-line afatinib in patients with } \\
\text { EGFRm + NSCLC in Japan: retrospective analysis of } \\
\text { LUX-Lung } 3\end{array}$ & $\begin{array}{l}\text { Yoshioka H, Kato T, Okamoto I, Tanaka H, Hida T, Seto T, } \\
\text { Kiura K, Tian Y, Azuma H \& Yamamoto N }\end{array}$ & 7566 & [9] \\
\hline
\end{tabular}

that has been accruing data since 2017, investigating the effect of sequential afatinib and osimertinib on overall survival in EGFR-mutation-positive non-small-cell lung cancer patients [7].

The journal has been fortunate to work with the GioTag group since early phases of the trial, with the first retrospective observational study demonstrating the feasibility of sequential afatinib and osimertinib therapy published in October 2018 [10]. It has been particularly interesting for our editors to follow the study's progress, to work on the interim results and even to see the results presented in the news [11-13].

Future Oncology have also continued our successful partnership with Altmetric to help authors measure the impact of their work more accurately. This year, special mention must go to the following articles the performed particularly highly:

- Germetaki et al. 'Blood-based RAS mutation testing: concordance with tissue-based RAS testing and mutational changes on progression' - the authors show good similarity between tissue and liquid biopsy results, suggesting liquid biopsy is a safe and viable alternative to more invasive testing [14];

- Yekedüz et al. 'A clinical dilemma amid COVID-19 pandemic: missed or encountered diagnosis of cancer?' - An interesting exploration of how chest CT scans were being used to diagnose COVID-19, and that this could present opportunities to diagnose cancer simultaneously [15];

- Pascual T et al. 'SOLTI-1503 PROMETEO trial: combination of talimogene laherparepvec with atezolizumab in early breast cancer' - a window of opportunity trial, evaluating the combination of an oncolytic virus with an anti-PD-L1 inhibitor in women with operable HER2-negative breast cancer [16].

Social media has become a crucial tool for publishers to help spread their research, so it is gratifying to see the extra attention this is bringing to authors' work. The journal's Twitter account (@fsgfon) has gained more than 250 followers over the course of the year and we are hoping this continues to grow to help us disseminate research more quickly.

\section{What have the editors been doing?}

This year, the coronavirus pandemic has meant that conferences have been made virtual and many have had to rethink how they collaborate, communicate and disseminate their work. The same goes for the journal - our editors and publishers have been working to offer new ways for authors to spread their research quickly and easily. Plain Language Summaries of Publications are one of these exciting new developments, but along with this we have introduced video abstracts, podcasts and Peak Behind the Paper interviews with Oncology Central. If you are interested in including these with your research, take a look at our website for more information (www.futuremedicine.com/authorguide/makingthemost).

Future Oncology publishes a number of special-focus issues each year to give our readers a comprehensive update on one particular topic. This year, we chose combination therapies for immuno-oncology and with the help of Laura Mezquita (Hospital Clínic de Barcelona, Barcelona, Spain) and Gonzalo Recondo (Centro de Educación Médica e Investigaciones Clínicas, Buenos Aires, Argentina) - guest editors for the issue - we produced a valuable resource for oncologists [17]. Of particular note are the articles by Ferrara et al. discussing atypical patterns of response to immunotherapy [18], and by John et al. exploring the applications of patient-specific multi-omics models in personalized combination therapy [19]. 


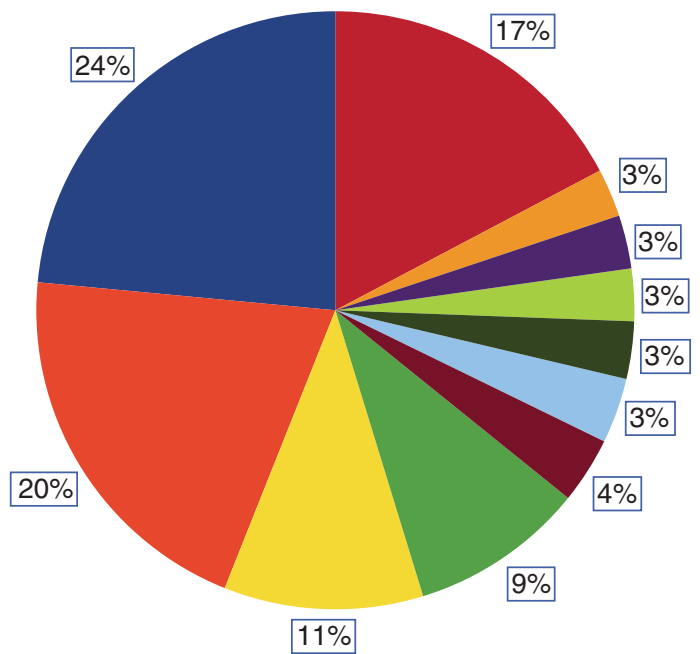

\begin{tabular}{|l|}
\hline - China \\
United States \\
United Kingdom \\
Italy \\
- Japan \\
Lebanon \\
- Germany \\
Australia \\
France \\
India \\
- Other
\end{tabular}

Figure 1. Papers published in Future Oncology during 2020, ordered by country.

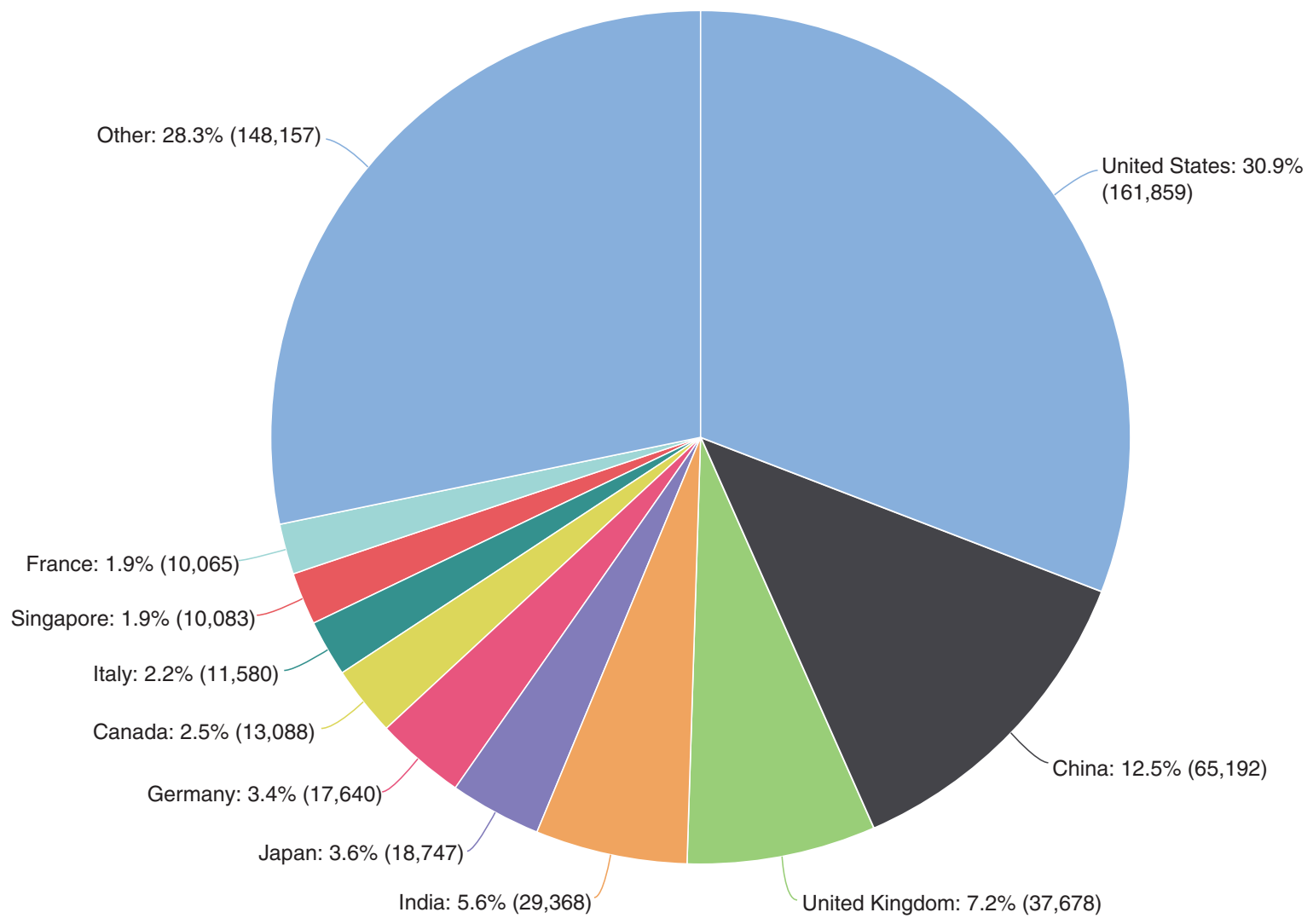

Figure 2. Readership in Future Oncology during 2020.

We always enjoy working on special-focus issues as it is a chance to work more closely with those in the field to publish impactful and helpful research. As we move into 2021, Future Oncology will begin publishing collections of past publications with a specific focus in mind, much the same as these special-focus issues. Keep an eye out for the first collection, due to be published quite soon, and make sure you send us any of your feedback.

To help us disseminate these collections, and to provide focused updates of journal articles for oncologists, Future Oncology and our partnered website Oncology Central are determined to work with each other more in 2021. This 
partnership also helps the journal disseminate digital enhancements to a wider audience, such as our recent podcast with Ardndt Vogel (Medizinische Hochschule Hannover, Hanover, Germany) [20]. I now write a monthly column for Oncology Central of the best articles in the journal so, if you have not already, be sure to go and visit the website and sign up (www.oncology-central.com).

And lastly, Future Oncology is pleased to introduce a new Senior Editor to the Editorial Board, Jackson Orem, inaugral Director of the Uganda Cancer Institute. Adam Dicker has sadly had to step down from his role, but we are looking forward to the future of the journal with Dr Orem as a key member of our team.

\section{Demographics of Future Oncology}

As well as looking back over the topics and the types of articles published in the journal, it is interesting to consider the source of the content (Figure 1) and where it is being read (Figure 2).

We are continuing to receive high-quality content from across the globe, most notably from Europe (33.5\%), Asia $(30.6 \%)$ and North America (22.5\%). It is also pleasing to see an increase in content from smaller countries such as Lebanon and Argentina.

Readership also remains broad and well-distributed across the globe. The highest number of readers are still located in North America (33.4\%) and Europe (14.7\%), but thanks to increased submissions from a more diverse range of countries, Future Oncology's readership has expanded to more areas of the world, particularly the Middle East and North Africa with increases in Lebanon, Egypt and Turkey. With the field of oncology continuing to advance so quickly, we look forward to seeing the global reach of the journal continue to grow.

As always, we are very grateful to all of our Editorial Board members, authors, peer reviewers and readers for supporting the journal, especially during such a challenging period of time. We look forward to working with you all again in 2021 - please do not hesitate to get in touch if you are interested in contributing to the journal.

Financial \& competing interests disclosure

L Gautier is an employee of Future Medicine Ltd, publisher of Future Oncology. The author has no other relevant affiliations or financial involvement with any organization or entity with a financial interest in or financial conflict with the subject matter or materials discussed in the manuscript apart from those disclosed.

No writing assistance was utilized in the production of this manuscript.

\section{References}

1. Dormer L, Walker J. Plain Language Summary of Publication articles: helping disseminate published scientific articles to patients. Future Oncol. 16(25), 1873-1874 (2020).

2. Tap W. ENLIVEN study: pexidartinib for tenosynovial giant cell tumor (TGCT). Future Oncol. 16(25), 1875-1878 (2020).

3. Tap WD, Gelderblom H, Palmerini E et al. Pexidartinib versus placebo for advanced tenosynovial giant cell tumor (ENLIVEN): a randomized Phase III trial. Lancet 394(10197), 478-487 (2019).

4. Brandes AA, Ardizzoni A, Artioli F et al. Fighting cancer in coronavirus disease era: organization of work in medical oncology departments in Emilia Romagna region of Italy. Future Oncol. 16(20), 1433-1439 (2020).

5. Elkaddoum R, Haddad FG, Eid R, Kourie HR. Telemedicine for cancer patients during COVID-19 pandemic: between threats and opportunities. Future Oncol. 16(18), 1225-1227 (2020).

6. Wozniak AM, Rallis KS. Incorporating teleoncology practices in the undergraduate medical curriculum. Future Oncol. doi: 10.2217/fon-2020-0798 (2020) (Epub ahead of print).

7. Hochmair MJ, Morabito A, Hao D et al. Sequential afatinib and osimertinib in patients with EGFR mutation-positive non-small-cell lung cancer: final analysis of the GioTag study. Future Oncol. 16(34), 2799-2808 (2020).

8. McDonald L, Carroll R, Harish A et al. Suspected cancer symptoms and blood test results in primary care before a diagnosis of lung cancer: a case-control study. Future Oncol. 15(33), 3755-3762 (2019).

9. Yoshioka H, Kato T, Okamoto I et al. Therapies after first-line afatinib in patients with EGFRm+ NSCLC in Japan: retrospective analysis of LUX-Lung 3. Future Oncol. 16(4), 49-60 (2020).

10. Hochmair MJ, Morabito A, Hao D et al. Sequential treatment with afatinib and osimertinib in patients with EGFR mutation-positive non-small-cell lung cancer: an observational study. Future Oncol. 14(27), 2861-2874 (2018).

11. Hochmair MJ, Morabito A, Hao D et al. Sequential afatinib and osimertinib in patients with EGFR mutation-positive non-small-cell lung cancer: updated analysis of the observational GioTag study. Future Oncol. 15(25), 2905-2914 (2019).

12. Boehringer Ingelheim. Final analysis of the observational GioTag study: sequential afatinib and osimertinib in patients with EGFR mutation-positive non-small-cell lung cancer. https://www.boehringer-ingelheim.com/press-release/giotag-final-data 
13. Feinberg B, Halmos B, Gucalp R, Tang W, Moehring B, Hochmair MJ. Making the case for EGFR TKI sequencing in EGFR mutation-positive NSCLC: a GioTag study US patient analysis. Future Oncol. 16(22), 1585-1595 (2020).

14. Germetaki T, Nicholls C, Adams RA et al. Blood-based RAS mutation testing: concordance with tissue-based RAS testing and mutational changes on progression. Future Oncol. 16(28), 2177-2189 (2020).

15. Yekedüz E, Karcioğlu AM, Utkan G, Urün Y. A clinical dilemma amid COVID-19 pandemic: missed or encountered diagnosis of cancer? Future Oncol. 16(25), 1879-1881 (2020).

16. Pascual T, Cejalvo JM, Oliveira M et al. SOLTI-1503 PROMETEO TRIAL: combination of talimogene laherparepvec with atezolizumab in early breast cancer. Future Oncol. 16(24), 1801-1813 (2020).

17. Recondo G, Mezquita L. Clinical efficacy, predictive biomarkers and response patterns of immunotherapy combinations for patients with cancer. Future Oncol. 16(23), 1659-1664 (2020).

18. Ferrara R, Matos I. Atypical patterns of response and progression in the era of immunotherapy combinations. Future Oncol. 16(23), 1707-1713 (2020).

19. John A, Qin B, Kalari KR, Wang L, Yu J. Patient-specific multi-omics models and the application in personalized combination therapy. Future Oncol. 16(23), 1737-1750 (2020).

20. Vogel A. Targeting FGFR2 in advanced cholangiocarcinoma: an interview with Arndt Vogel. Future Oncol. 16(30), 2373-2374 (2020). 